\title{
Physical attractiveness, issue agreement, and assimilation effects in candidate appraisal
}

\author{
James N. Schubert* \\ Department of Political Science \\ Northern Illinois University \\ 415 Zulauf Hall \\ Dekalb, IL 60115 \\ Margaret Ann Curran \\ Office of Research, Evaluation, and Policy Studies \\ College of Education \\ Northern Illinois University \\ Dekalb, IL 60115

\section{Carmen Strungaru} \\ Department of Animal Physiology, Biophysics, and Ethology \\ Faculty of Biology \\ University of Bucharest \\ Bucharest, Romania
}

*This paper is published posthumously in honor of Schubert's founding role in the Association for Politics and the Life Sciences, his many contributions to the journal as both an author and editorial board member, and his innovative contributions to biopolitical scholarship throughout his career. The research on which this article is based was funded by a grant from the National Institute of Mental Health for a study of "Physical Appearance and Leadership Selection." Findings from the study were covered by the Wall Street Journal and other prominent newspapers in the run-up to the 2000 presidential election. Author affiliations were those at the time this research was originally presented.

\begin{abstract}
This study examines the cognitive and affective factors of candidate appraisal by manipulating candidate attractiveness and levels of issue agreement with voters. Drawing upon research in evolutionary psychology and cognitive neuroscience, this analysis proposes that automatic processing of physical appearance predisposes affective disposition toward more attractive candidates, thereby influencing cognitive processing of issue information. An experimental design presented attractive and unattractive candidates who were either liberal or conservative in a mock primary election. The data show strong partial effects for appearance on vote intention, an interaction between appearance and issue agreement, and a tendency for voters to assimilate the dissimilar views of attractive candidates. We argue that physical appearance is important in primary elections when the differences in issue positions and ideology between candidates is small.
\end{abstract}

Key words: Political evaluation, issue agreement, assimilation effects, candidate appraisal, physical attractiveness, electoral viability, visual cues

doi: 10.2990/30_1_33

Politics and the Life Sciences • Spring 20 i I $\bullet$ VOl. 30, No. I 


\section{Schubert, Curran, and Strungaru}

B eing physically attractive matters for electoral success. An expanding literature finds that people feel positively toward and regularly vote for more physically attractive candidates. Still lacking is a theoretical explanation for how and when levels of attractiveness influence voting decisions. This paper develops a theoretical framework that assesses the influence of physical attractiveness on vote intention under varying levels of issue agreement between candidates and voters.

The theoretical premise proposed here investigates how affective and cognitive attitudes interact to shape voting behaviors. Physical attractiveness determines affective attitudes, and levels of issue agreement influence cognitive evaluations. There are four conditions under which affective and cognitive dispositions are expected to interact: positive affect with cognitive agreement, positive affect with cognitive disagreement, negative affect with cognitive agreement, and negative affect with cognitive disagreement. Do consistently positive or negative dispositions have an additive or multiplicative effect on candidate appraisal and issue agreement? Do they increase or decrease vote intention? Or, do they have some other effect? Conversely, do contradictory affective and cognitive dispositions cancel each other out, or does one trump the other? The model developed in this paper draws upon studies of political perception that document voter tendencies toward perceptual distortion in candidate appraisal, including both assimilation and contrast effects, ${ }^{1,2}$ such that voters may distort or disregard their perception of preferred candidates who have incongruent issue positions.

Several studies in social psychology conducted in the 1980s explored the role of physical appearance in social judgment, ${ }^{3}$ and some extended this concern to the problem of candidate appraisal in electoral behavior. $^{4,5,6,7} \mathrm{~A}$ common finding was that physical attractiveness significantly affected judgments of electability or vote intention. Exploratory in nature, these studies lacked a theoretically based casual model explaining why and how appearance effects operate in candidate appraisal. More recently, two lines of behavioral research provide the theoretical grounds for understanding appearance effects in candidate appraisal. First, major gains in evolutionary psychology have applied the "good genes" theory from biology to understand human perceptions of beauty and physical attractiveness. ${ }^{8,9,10}$ Additionally, substantial progress has been made in cognitive neuroscience detailing how the brain processes facial information to solve problems involving facial recognition and emotional display. ${ }^{11,12}$ This research supports a model of emotional response where the brain automatically predisposes preferences both independently of, and sequentially prior to, the conscious processing of semantic information. According to this model, neurophysiological mechanisms predispose voter preferences and, under conditions of inconsistency, activate assimilation and contrast effects in processes of political perception.

\section{Appearance and electability}

Previous research supports the proposition that perceptions of attractiveness, cued by facial morphology, shape perceptions of candidate electability. 5,13,7 Appearance, style, and other idiosyncratic personal information may have special relevance for multicandidate elections when partisan identification is constant, political information scarce, ${ }^{14}$ or issue positions less differentiated, as in primary elections in the United States. ${ }^{15,16}$ Wyer and Ottati summarize the literature on candidate appraisal with specific attention to how voters form impressions of new candidates. ${ }^{17}$ They posit that voters rely heavily on partisan identification and personal appearance when issue information is in short supply. In contrast, when voters begin acquiring information about candidate issues and values, appearance effects dissipate.

If subjects receive information about a previously unknown candidate in the absence of information about the candidate's stands on specific issues, they form a general concept of the candidate on the basis of (a) party affiliation, (b) physical appearance and mannerism, or both (p. 287).

Popkin's discussion of impression formation in primary elections supports a model in which idiosyncratic personal information plays an important role in candidate appraisal. ${ }^{18}$ Indeed, he observes that, "personal information can drive more relevant political information out of consideration" (p. 166). Although not testing the relative effects of personal and political information, Rosenberg and colleagues examined the effects of physical appearance on vote choice with 


\section{Assimilation effects in candidate appraisal}

candidates' party affiliation and ideology controlled through experimental design. ${ }^{5}$ Across different conditions and subject populations, appearance consistently had significant and substantial effects on vote choice.

Wyer and colleagues examined the effects of favorable versus unfavorable appearance and speech style on candidate appraisal. ${ }^{7}$ To permit measurement of issue and ideological agreement, candidates were alternatively presented with liberal or conservative ideologies. The study found significant appearance or "style" effects, but only under the condition of issue disagreement. No significant differences emerged in vote intention between favorable and unfavorable appearances when voters agreed with the candidates' issue positions or ideology.

Neither the Rosenberg nor Wyer studies present a causal explanation of the correlation between appearance and vote intention. We posit that an assimilation effect in perceptions of the candidate's political values may explain how attractive candidates appeal to voters who do not agree with them. Assimilation effects in political judgments occur when voters perceive a candidate or party's values as more similar to their own than warranted by the facts. ${ }^{1,2,19}$ A tendency to assimilate views of attractive candidates accounts for Wyer and colleagues' findings that the correlation between appearance and vote choice is conditional on issue disagreement. Under conditions of issue agreement, there is no assimilation and therefore no correlation between physical appearance and vote choice.

This literature supports two propositions: first, that appearance matters for vote choice when political values are held constant; and, second, that appearance affects vote choice most when voters disagree with candidates' political values. The Rosenberg study simulated runoff elections between two candidates but Wyer and colleagues did not present a competitive choice. Neither study employed the two-factor manipulation necessary to simultaneously examine the effects of appearance and issue agreement and thereby test the assimilation hypothesis.

Two theoretical questions of practical electoral significance emerge from this literature. Frist, given a field of ideologically similar candidates, such as in a primary election, do more attractive candidates have a competitive advantage? Second, where political values vary among candidates, do more attractive candidates benefit from the tendency of less politically proximate voters to assimilate their views?

\section{The psychology of appearance effects}

Drawing on research in cognitive neuroscience, we propose that appearances matter in candidate appraisal because human brains automatically process facial images quickly (on the order of tens of milliseconds) and are neurologically predisposed to prefer some physical features more than others.

\section{Facial processing}

Neuroscientists studying facial image processing find that humans have specialized neurological capabilities for processing facial information that provides a means for exploring how the brain processes information more generally. ${ }^{11,12}$ Using brain imaging techniques and electrodermal measurements, also known as event-related potentials (ERPs), a growing number of studies have directly observed the activation of discrete areas of the brain when engaged in different facial processing tasks. Central problems of this research include understanding discrimination between familiar and unfamiliar faces, identification of familiar faces, and recognition of positive and negative emotional displays.

Findings from this research reveal the specialization of the brain in facial processing tasks. Clusters of neurons that fire in response to familiar facial stimuli are located in the right middle temporal gyrus and left prefrontal cortex, but the bilateral posterior cingulate gyri and right occipital cortex fire neurons when faces are unfamiliar; ${ }^{20}$ and, when processing emotional displays, neurons are activated in the amygdala. ${ }^{21,22}$ Current models propose parallel processing of facial image data for familiarity and for emotional display, ${ }^{23,24}$ and research finds that response latencies range from $70-130 \mathrm{~ms}$ for facial recognition tasks. ${ }^{25}$ During this one-tenth of a second, the brain analyzes the morphological structure of a face, searches memory for a matching image, analyzes the details of muscle controlled patterns that define emotional expression, ${ }^{11}$ and begins searching for facial identity. Priming either by repetition or prior exposure to a familiar name reduces latency (i.e., shortens time to recognition) to familiar faces. ${ }^{12}$ 


\section{Schubert, Curran, and Strungaru}

One implication of this research is that even well adapted voters may not be deeply processing semantic information about candidates, ${ }^{26}$ given that facial processing occurs almost instantaneously upon exposure to a candidate's face every time it is encountered. The effect of priming on response latency implies that significant media exposure facilitates facial processing. The more familiar the face and faster the response, the more likely it is that individuals process image data before any cognitive processing of semantic information.

Studies of pathologies in facial processing provide insights into the interrelationship of visual and semantic information processing. Prosopagnosia is a clinical condition in which patients cannot recognize faces they have seen before that should be familiar. ${ }^{12}$ In such cases, individuals do not remember familiar faces and cannot associate identities with faces. This condition results from lesions in the occipito-temporal regions of the cerebral cortex. Several studies using electrophysiological measurements have found that the brains of prosopagnosia patients respond to familiar faces, even though the patient does not remember having seen them before and cannot connect faces and names. Findings of this phenomenon, known as covert recognition, ${ }^{27,28}$ reveal that facial processing is largely automatic, or hard-wired, and occurs independently of cognitive processing. As Young ${ }^{12}$ comments:

For all neurologically normal people, recognition is mandatory. ${ }^{29}$ We cannot look at a familiar face and decide whether or not to recognize it; no matter how hard we try. The operation of the recognition system proceeds automatically, outside conscious control (p. 294).

Implied by this research is the finding that visual and cognitive processing happens by way of two separate pathways in the brain. As voters view a televised news report or a campaign ad, they simultaneously analyze the visual and semantic data. Voters process visual images with response latencies equal to just a few frames of video exposure, which in North America rolls by at a rate of 30 frames per second.

Two widely cited anecdotes illustrate the potential relevance of automatic facial processing for electoral politics. One is the Reagan Administration's positive response to a very negative CBS News report by Lesley Stahl about Ronald Reagan during the 1984 election. ${ }^{30}$
Reagan's campaign staff loved the report, arguing that "the great pictures of Ronald Reagan... are overriding your message because they conflict with your message" (p. 409). Also illustrating the political significance of automatic facial processing is the different response of television viewers and radio listeners to the first NixonKennedy debate of 1960 . Television viewers, so the conventional wisdom goes, saw the negative visual images of Nixon and evaluated him more negatively than the telegenic Kennedy. ${ }^{31}$ To reiterate, humans process visual images automatically and this highly efficient operation gives the visual evaluation of candidates temporal priority over cognitive assessments that do not happen as rapidly.

\section{Evolutionary psychology}

Evolutionary psychology also reveals that voters may bring phylogenetically adapted biases or predisposed preferences to bear in processing facial images. ${ }^{9,32}$ Cross-cultural studies provide a growing body of evidence that humans favor symmetrical faces, ${ }^{33,34}$ faces with an average alignment of features, ${ }^{35,36,37}$ and faces revealing enhanced secondary sexual characteristics, such as cheekbone prominence and large lower jaw size in males-and consider them to be more attractive than others ${ }^{38,39,10,40,41}$ Even infants at six months of age prefer symmetrical and average faces. ${ }^{42,35,43}$ One study reports that such preferences emerge in infants within days after birth. A consequence of these deep-rooted preferences is high agreement in ratings of facial attractiveness across different groups. ${ }^{43}$

Contention in this literature is not in the correlation of facial morphology with attractiveness judgments but the relative strength of these effects, the interaction of symmetry and averageness in attractiveness judgments, ${ }^{44,45}$ and the causal explanation of these biases. ${ }^{46}$ Whether these preferences originate from a neurological averaging of facial images that approximate population averages ${ }^{43}$ or reflect a phylogenetic adaptation, ${ }^{47}$ the fact that humans share certain fundamental preferences for adult faces indicates a neurophysiological basis for attractiveness judgments that might explain appearance effects in candidate appraisal. Indeed, there is evidence from event-related potential studies that positive versus negative affective response to faces activates different areas in the brain for facial processing. ${ }^{48}$ This reinforces the interpreta- 


\section{Assimilation effects in candidate appraisal}

tion that affective responses to facial images are quick, automatic, and precede cognitive awareness.

\section{Appearance and trait attributions}

Other relevant research explores appearance-based attributions of personality traits. Associated with attractiveness is a "halo effect" where individuals attribute positive personality characteristics to attractive persons, including competence, likability, dominance, and honesty-all traits associated with political leaders. ${ }^{49}$

Facial dominance is a dimension of appearance rated with high reliability both within and across cultures. $^{50,51}$ These ratings respond to enhanced secondary sexual characteristics in male faces, especially large lower jaw size, and prominence of both cheekbones and eyebrow ridges. ${ }^{10}$ Mazur and Mueller report that ratings of facial dominance for West Point cadets based on yearbook photographs with standard poses, were positively associated with status attainment while at the Academy, as well as with attainment of General rank decades later in their careers..$^{52,53,40}$ Basal testosterone levels in puberty condition secondary sexual characteristics in males. One explanatory hypothesis of the leadership selection effect is that facial features serve as cues to heightened basal testosterone levels that, in turn, are associated with competitive and assertive behavioral patterns, ${ }^{54}$ contributing to leader stereotypes.

Zebrowitz, Voinescu, and Collins conducted research on "demeanor bias" designed to explore factors that contribute to common perceptions of faces as honest or dishonest. ${ }^{55}$ They found that babyfaceness or neotany, attractiveness, facial symmetry, and larger eyes contributed to perceptions of honesty and "wide eyed innocence." Geldard, Maurer, and Carney report "modest" significant preferences for larger eyes in adult faces in research with five-month old infants. ${ }^{42}$ This emerging literature on facial morphology and trait attribution indicates that not only are some facial features preferred over others, but also that this preference extends to the attributions of desirable and undesirable personality characteristics that play a direct role in assessing candidates for political office. ${ }^{56}$

Television, print media of all kinds, brochures, posters, banners, and the Internet bombard voters with visual images of candidates. Neuroscience findings highlight how the brain processes these images very quickly, priming and possibly shaping subsequent cognitive information processing activity. Evolutionary psychology suggests that voters bring to their visual processing tasks certain preferences, biases, or predispositions, potentially favoring some candidates over others. Research on trait attributions suggests that these biases encompass desirable or undesirable personality characteristics. Taken together, these findings reveal not only why physical appearances matter for candidate appraisal, but also which morphological configurations voters prefer.

\section{Hypotheses}

An experimental design tested first whether attractive candidates have a competitive advantage and, second, how levels of ideological agreement between candidates and voters moderate the effect of candidate attractiveness. It is assumed that voters apply stereotypes in selecting candidates for executive leadership positions, such as president or governor. Stereotypes applied to executive leaders differ from those applied to candidates for Congress or lower offices. The dependent variable, vote intention, is conditional on executive leadership office.

Physical appearance and style may affect vote choice because voters share stereotypic expectations of how leaders should look and behave. The literature on evolutionary psychology and cognitive neuroscience supports the proposition that people are predisposed to prefer certain appearances to others, including attractiveness and dominance as cued by facial morphology. Additionally, voters make trait attributions, including competence and ability, based on physical appearance. Stereotypes of leaders reflect these predisposed preferences and voters express them in judgments of candidate electability, also referred to as viability, for leadership offices in popular elections. Given that voters are unlikely to choose candidates judged low in electability, ${ }^{57}$ it can be predicted that:

$\mathrm{H}_{1}$ : Under low information conditions or with other relevant factors, such as background, character, and information on political values held constant, voters will be more likely to vote for candidates with positive appearances based on electability ratings.

Of course, candidates vary along a continuum of attractiveness and voters often choose between two or more candidates. The size of the effect of physical 


\section{Schubert, Curran, and Strungaru}

appearance on vote intention depends on the size of the contrast in candidate attractiveness. Thus, we predict that:

$\mathrm{H}_{2}$ : The greater the contrast in appearance-based electability ratings of candidates, the greater the effect of physical appearance on vote intention.

Relevant literature supports the assumption that the processing of visual information about candidates by voters is automatic and precedes cognitive processing of data about them. Therefore, and counter to Wyer and colleagues, ${ }^{7}$ appearance-based electability evaluations should contribute to vote intention regardless of issue agreement or disagreement. The third hypothesis therefore predicts that:

$\mathrm{H}_{3}$ : Appearance-based electability evaluations will have a significant effect on vote intention, independent of the level of issue agreement between voters and candidates.

If voters share and apply a stereotype of electability to candidate evaluations, then we can assume that they will dismiss candidates who do not meet the stereotype. As cognitive misers, ${ }^{26}$ voters are unlikely to waste their votes on unelectable candidates and invest cognitive resources in evaluating semantically encoded information about candidates with low electability, including information about issue positions. Therefore,

$\mathrm{H}_{4}$ : The greater the appearance-based electability evaluations of candidates, the weaker the effects of issue agreement upon vote intention.

Notably, this hypothesis emphasizes the importance of stereotype matching in candidate appraisal. Candidates who fail the appearance test receive little further consideration.

More than a generation of research by Granberg and collaborators reveals that voters distort positions of parties and candidates based upon their affective dispositions toward them. Implicit stereotypes, rooted in human neurobiology and affective dispositions, might activate cognitive processes of assimilation and contrast. Granberg ${ }^{2}$ summarizes these effects in the following propositions:

People tend to assimilate when attributing a position to a preferred party or candidate. The degree to which assimilation of a preferred candidate occurs is a direct function of the level of positive affect felt by the person toward the preferred candidate. The tendency to assimilate in perceiving the position of a preferred party or candidate is pervasive, occurring at both the level of the average citizen and extending to people in elite positions (pp. 85-86).

If people do display positive affect toward faces with selective morphological features, then Granberg's view that people will assimilate the views of candidates toward whom they are positively disposed should be correct. Hence, the final hypothesis posits that:

$\mathrm{H}_{5}$ : The greater the appearance-based electability rating of a candidate, the greater the assimilation of a candidate's political values by voters who do not share them.

\section{Research design}

An experiment exposed subjects to a mock primary election campaign containing stimuli for four candidates presented in a $2 \times 2$ factorial design that manipulated appearance and ideology. Candidates included a liberal and conservative with high appearance-based electability ratings and a liberal and conservative with low electability ratings. Degree of attractiveness was held constant across ideological lines: there were two versions of the experiment conducted such that the attractive liberal in the first experiment was the attractive conservative in the second.

Images of political candidates used in the experiment were selected from the 16 official candidates for president in the 1996 Romanian national elections. Included in each wave of evaluation were the incumbent, two major party candidates, and one minor party representative. More than 150 American subjects in four different replications of the experiment, including undergraduate and adult professional samples, rated the electability and attractiveness of the 16 candidates with high levels of between-subjects agreement (Cronbach's alpha $=.95$ ). These ratings strongly correlated with those yielded by a replication of the experiment in Jakarta, Indonesia (and, tentatively, a sixth in the Trobriand Islands). The ratings revealed significant differentiation between the 16 candidates in ratings of pictures and video clips of speaking behavior 


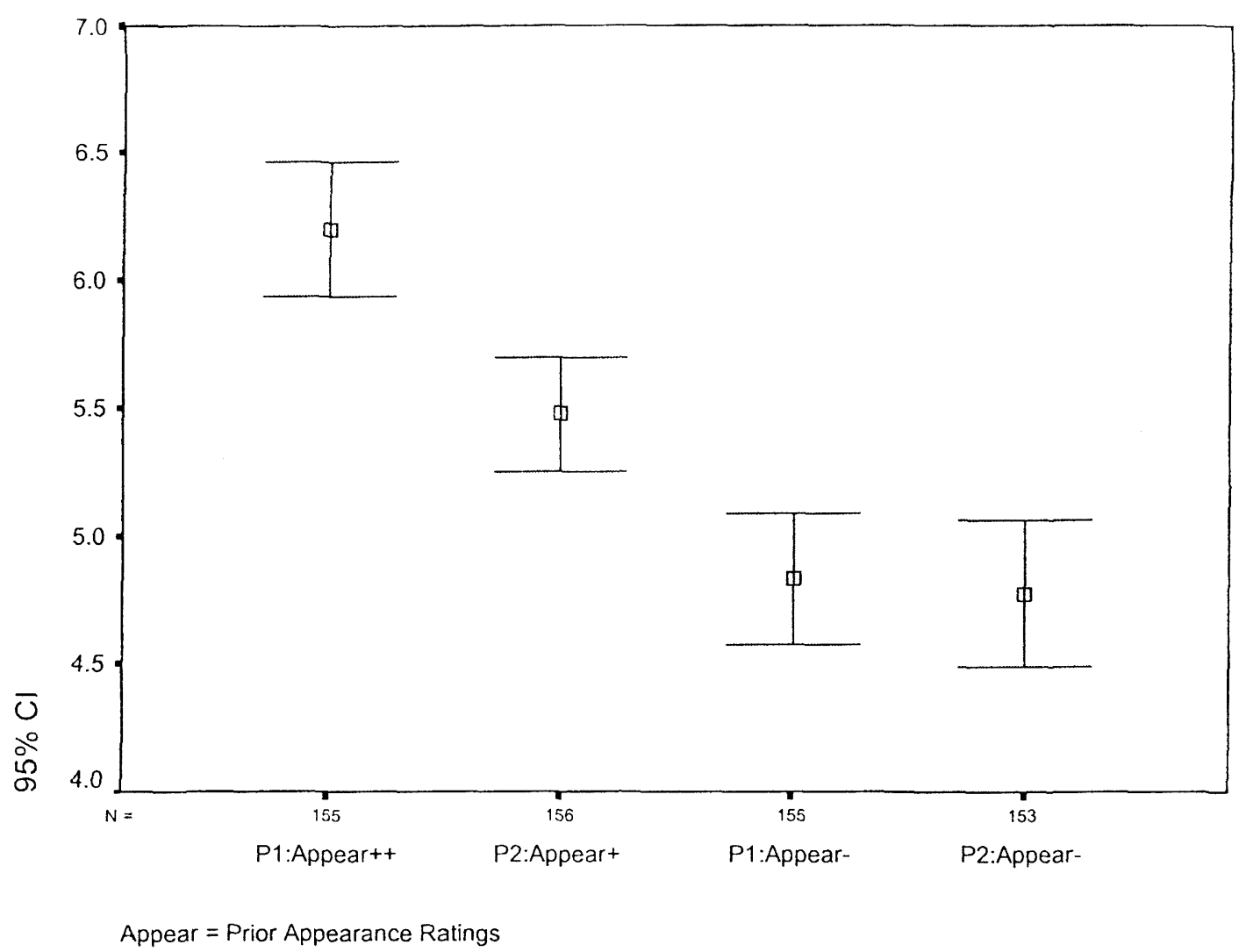

Figure 1. Means and confidence intervals for candidate pair electability ratings.

in televised national debates. One candidate received very positive ratings in both appearance and style, one was above average in appearance and very positive in style, and two were slightly below average in both appearance and style. As Figure 1 reveals, this design does not produce artificially contrived variance on the appearance factor that would skew results.

The experimental stimuli consisted of video clips and campaign pamphlets that provided voters with a visual image of the candidates and issue-based information to activate cognitive processing. Subjects first viewed a 20 -second video clip of the candidate taken from a nationally televised debate that standardized image size, camera angle, dress, and background setting. They then rated the candidate on a 9-point electability scale. Subjects next read a campaign pamphlet for each candidate, which contained a picture, a name-Bob Miller, Mike White, Joe Nelson, or Jim Smith-and slogan on the first page, and four issue statements with a picture on the two inside pages. Pictures came from actual campaign literature of the candidates in the Romanian election. Pamphlets included statements drawn from the web pages of U.S. senators and representatives with strong liberal or conservative policy positions. Issue statements for each candidate addressed three issues: abortion, gun control, and the Clinton impeachment. A fourth issue position included in the pamphlet was either school prayer or school vouchers. For example:

Liberal: It is imperative that we guard the safety of our children at school and at home, which obligates us to restrict the number of guns on our streets. Too many children are killed every day as a result of irresponsible gun owners and the easy availability of guns. I support legislation to increase the waiting period for anyone wanting to buy a gun and to limit access for everyone convicted of crimes to ownership of guns.

Conservative: I will actively work to protect individual liberty and freedom by opposing gun control legisla- 


\section{Schubert, Curran, and Strungaru}

tion. I am concerned that waiting periods and bans, as well as taxes on ammunition and strict transfer laws, will not deter criminals from obtaining guns. Such measures only serve to infringe on the rights of honest citizens, not protect them from criminals.

After reading the pamphlet, subjects evaluated each candidate on several posttest items described below. After rating the first candidate, subjects watched another video clip, read another pamphlet, and evaluated the second candidate. Subjects were recruited from undergraduate classes for both versions of the experiment-112 subjects for the first version and 64 for the second version. Two groups came from a state college in New York, one from a state university in Illinois, and one from a state university in Arkansas. Previous experiments found virtually no differences between undergraduate and adult ratings of candidates; therefore, use of student samples was deemed justified.

A pretest administered at least a week before the experiment assessed subject attitudes, media use, demographics, and political orientations. In addition, the pre-experiment questionnaire included items addressing attitudes toward the policy issues presented as stimuli in the campaign brochures. The posttest instrument included the electability measure described above ("Regardless of whether you would vote for this candidate, what is your overall impression of the electability of this candidate?"), scales for rating the perceived liberal and conservative values of the candidates, and a vote intention scale. Similar to previous studies, subjects rated candidates on 9-point trait attribution scales for competence, honesty, compassion, likability, and leadership ability. ${ }^{7}$

\section{Reliability and validity}

\section{Electability}

To test the reliability of the manipulation of candidate appearance, subjects rated candidate electability after watching a brief, silent video clip of speaking behavior in a televised debate and before exposure to political information in the campaign brochure. Mean ratings were calculated across the two versions of the experiment because the information on issues that distinguishes them was not available to the subjects when they recorded their responses. Figure 1 presents the means and 95 percent confidence intervals for candidate electability ratings. The candidate rated most favorably in prior research was judged significantly more electable that the other three in this experiment. The second candidate selected for positive appearance was rated as significantly more electable than the two selected for less attractive appearance. There was virtually no difference in the ratings for the latter two candidates. In sum, these data show that the stimuli produced the intended manipulation of candidate appearance, including a high and low contrast condition within the candidate pairs.

\section{Attractiveness and trait attributions}

A test of concurrent validity involves the association of attractiveness with the attribution of leadership traits. Indeed, trait attributions may partially mediate the effects of physical appearance on evaluations of electability. In addition to the "halo" effect for attractiveness, previous research ${ }^{5,7}$ has attributed competence, leadership ability, honesty, compassion, and likability to more attractive candidates. Figure 2 reports attribution data on each of these characteristics for both candidate pairs. Subjects evaluated candidates on the trait scales after exposure to both the video clips and campaign brochures. Means for each candidate were calculated across the liberal and conservative portrayals, effectively holding political values constant. Within each pair of the five trait scales, the more electable candidate received a higher mean rating. In addition, the mean differences were statistically significant with the exception of compassion for the low contrast pair. The size of the difference is somewhat greater in the high contrast pair for ratings of competence, leadership ability, compassion, and likability but not honesty. However, the $t$ values are much greater for the high contrast pair on each of the traits. These data confirm that the attractiveness halo effect extends to the realm of candidate appraisal.

\section{Results}

\section{Electability and vote intention}

The hypothesized effect of electability judgments on vote intention assumes that voters are more willing to consider voting for candidates they consider electable and less willing to waste their votes on unelectable 


\section{Assimilation effects in candidate appraisal}

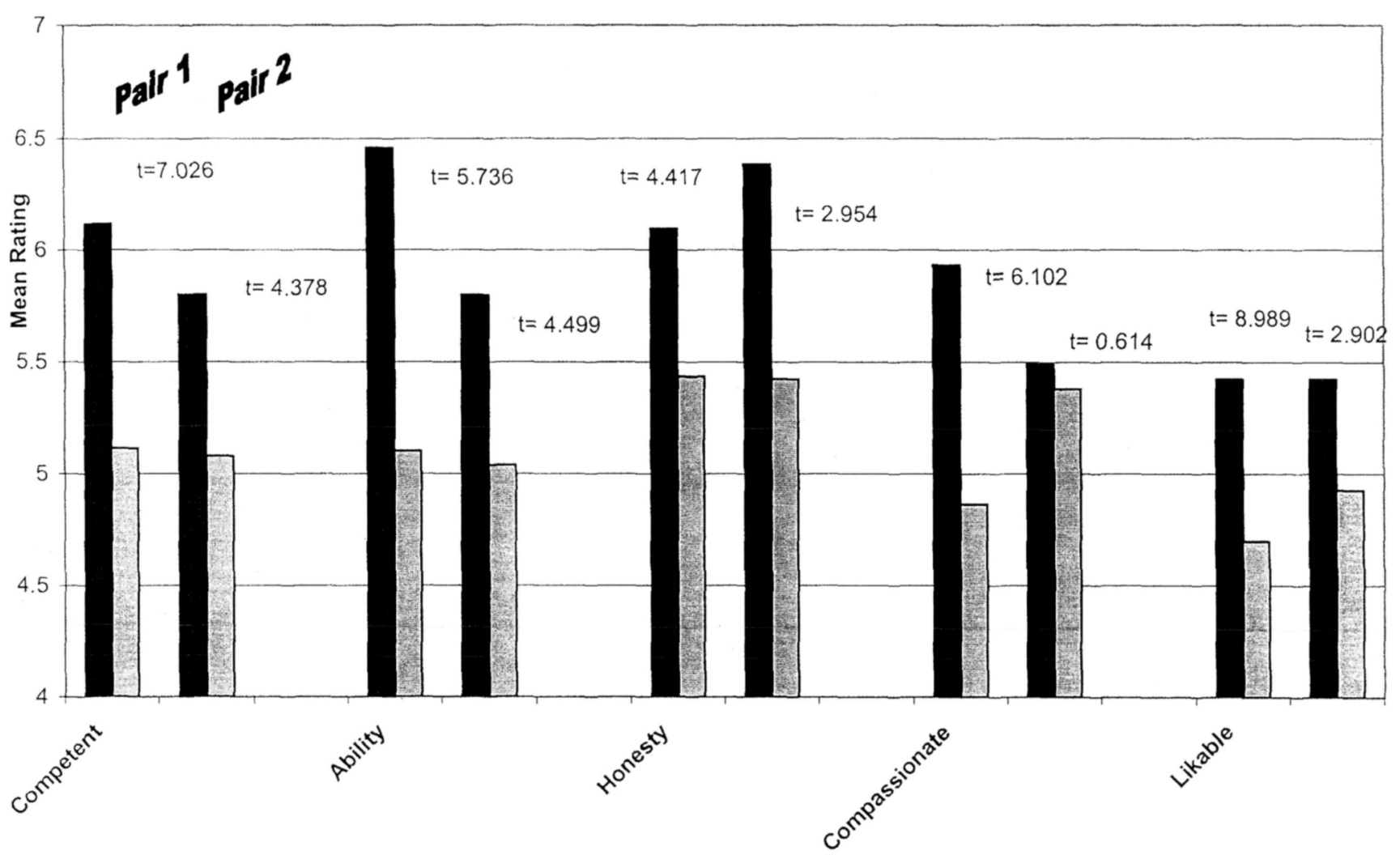

Appear+ appear-

Figure 2. Trait attributions of candidate pairs.

candidates. Figure 3 plots the relationship between electability and vote intention for each of the four candidates. Case points are randomly dispersed in the plots to display clusters along the least squares line.

A striking result in these data is the similarity in the patterns of the effects. Although central tendency in electability varies across the four candidates, the slopes are nearly identical-the greater the electability rating, the greater the vote intention. Cases cluster in the higher electability and higher vote intention quadrant of the plots for the two more politically attractive candidates and in the lower electability and lower vote intention quadrant for the less attractive candidates.

To explore the effects of the contrast in appearance between candidates, significance tests for the mean difference in vote intention were calculated within pairs, where the issue positions presented (liberal or conservative) were identical. For the high contrast pair (\#1), the mean difference in vote intention was 1.621 $(t=8.263, p<0.000)$ and for the low contrast pair $(\# 2)$, the mean difference was .661 $(t=3.408, p<$ $0.001)$. Thus, with the effects of issue agreement held constant, vote intention was significantly greater for the more attractive candidate within a pair. In addition, the greater the contrast between two candidates, the greater the difference in vote intention.

\section{Electability, issue agreement, and vote intention}

Subjects received brochures about each of the candidates, with very liberal or very conservative subjects receiving brochures from candidates on the opposite side of the political spectrum. The difference between a subject's self-placement on a scale of political ideology, ranging from very liberal to very conservative, provided an indicator of issue agreement or disagreement with the candidates. To explore the interaction between appearance and ideological agreement, subjects reporting liberal or very liberal values 
Pair 1: Appearance++

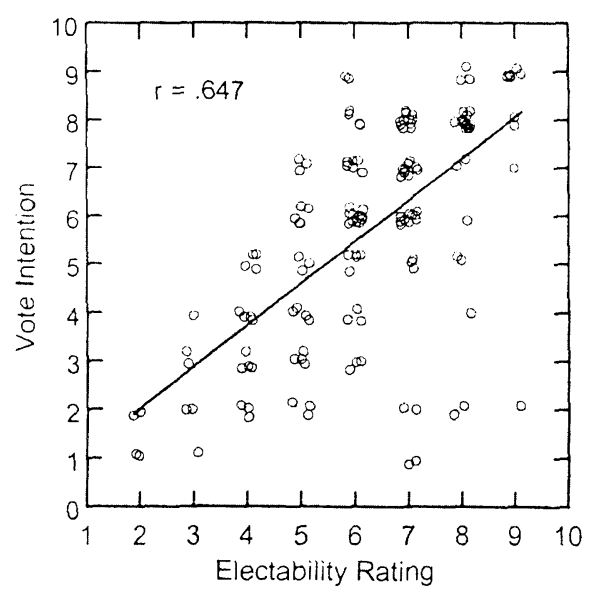

Pair 1: Appearance-

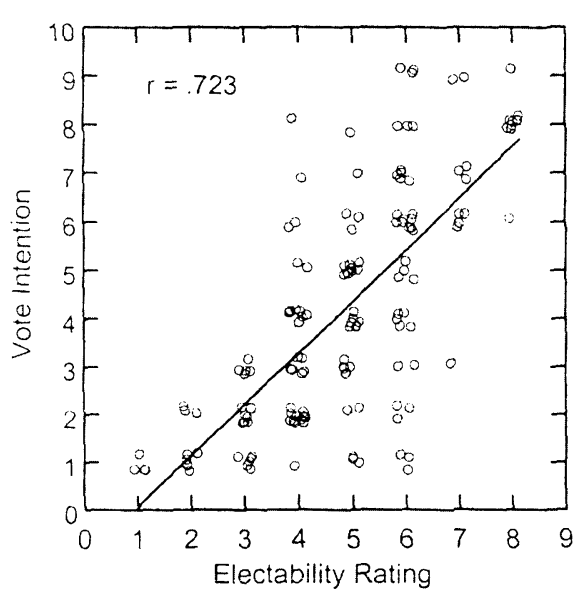

Figure 3. Electability rating and vote intention.

were classified as in agreement with liberal candidates, in disagreement with conservative candidates, and vice versa for conservative subjects. Moderates were placed in a partial agreement category.

The data in Table 1 reveal that politically attractive candidates enjoy a decided advantage under each of the conditions of ideological agreement. Vote intention in each category is approximately the same for the two less attractive candidates and correlated with value agreement for all four. In the high contrast pair (Pair $1)$, the attractive candidate and the size of the difference increased with greater disagreement. In the low contrast pair, the differences are smaller but significant
Pair 2: Appearance+

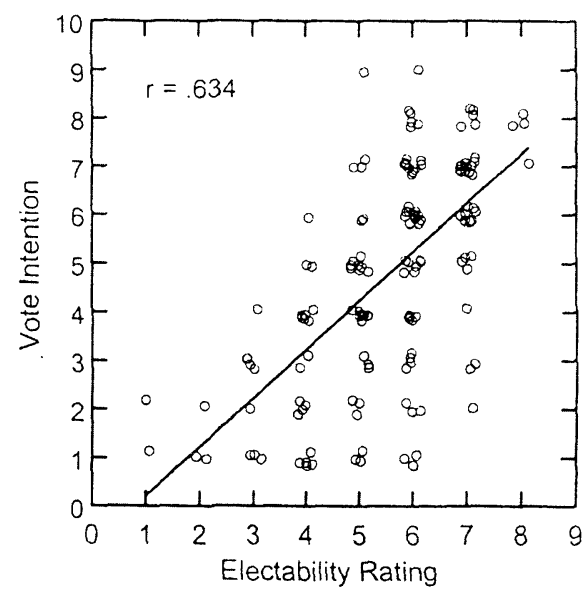

Pair 2: Appearance-

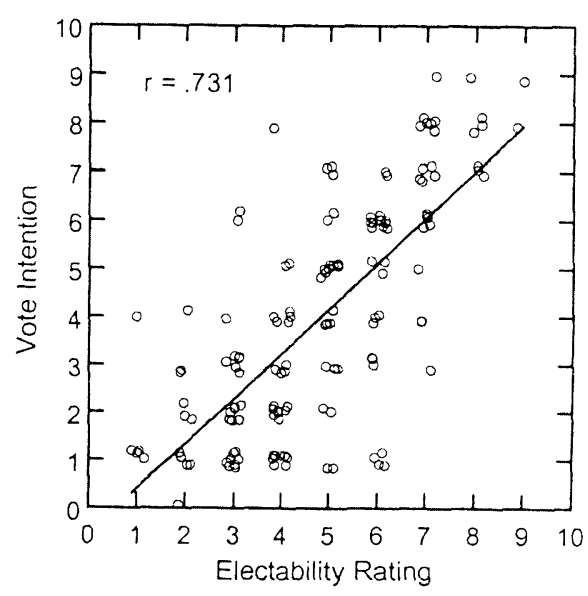

in a one-tailed test. These data clearly contradict the finding of Wyer and colleagues that appearance effects are conditional on political disagreement, although the effect is greater under disagreement in the high contrast pair.

A second approach to measuring agreement involved analyzing subject positions on the set of items in the pretest that included the issues addressed in the candidate brochures. Responses to five issue questions were entered into a principal components analysis and two factors were extracted that accounted for 27.1 percent and 24.4 percent of the total variance after varimax rotation. On the first factor, capturing social 


\section{Assimilation effects in candidate appraisal}

Table 1. Appearance, value agreement, and vote intention.

\begin{tabular}{ccccc}
\hline \hline Subject/candidate ideology & Pair 1 appearance ++ & Pair 1 appearance - & Pair 2 appearance + & Pair 2 appearance - \\
\hline Agreement & 6.580 & $5.350(p<0.001)$ & 5.720 & $5.030(p<0.067)$ \\
Mixed & 5.700 & $4.030(p<0.001)$ & 4.840 & $4.110(p<0.031)$ \\
Disagreement & 4.950 & $3.050(p<0.001)$ & 3.760 & $3.250(p<0.107)$ \\
\hline
\end{tabular}

Data are mean values. Probabilities are two-tailed for Student's $t$.

liberalism, loadings for attitudes toward abortion, prayer in schools, and impeachment were .792, .742, and .396. The second factor, capturing feminist values, discriminated positive attitudes toward women's' rights (.806) and negative attitudes toward gun control $(-.749)$. Factor scores for subjects on each principal component were subsequently used in regression analysis.

Given that the second version of the experiment reversed the ideological portrayal of the candidates to provide a consistent measure of attraction, the second version reversed the signs of the factor scores. For example, a very liberal subject who was in agreement with Pair 1 candidates in the first version, would be in disagreement in the second. Reversing the signs for subjects in the second version transformed the indicator from one of liberalism or conservatism to one of agreement or disagreement with Pair 1 candidates. For similar reasons, responses on the ideological selfplacement scale were transposed for subjects in the second version of the experiment for analyzing the effects of issue agreement on vote intention. Finally, because the sample size for the two versions of the experiment were unequal, cases were weighted by the proportionate contribution of their subsamples to the whole.

The data in Table 2 address the third and fourth hypotheses. Hypothesis 3, that appearance-based electability ratings have significant partial effects on vote intention, receives substantial support in these results. Appearance-based electability ratings had strong and significant effects on vote intention for all four candidates, although slightly less so for the most attractive candidate. Issue agreement, on the other hand, was important primarily for the attractive candidates, although ideological proximity had significant, albeit weak effects for one less attractive candidate.

Results for the liberal issue agreement factor bear directly on Hypothesis 4. Here, the effect size and significance increase with higher electability ratings. Considering the less electable candidates, subjects did not utilize available information on issue agreement in reaching decisions on vote intention. Results are weak and inconsistent for feminist issue agreement. The findings for social liberalism, however, suggest that voters may not seriously consider the issue position and political values of candidates who do not match their appearance-based stereotypes of political leaders.

\section{Physical appearance and assimilation effects}

Because candidates had relatively extreme issue positions, perceptions of candidate ideology hypothetically might range from accurate estimations to exaggerated similarity. Figure 4 plots subject ratings of candidate ideology for Pair 1 in relation to ideological self-placement, with untransposed responses, to illustrate the measurement of assimilation effects. Overall, subjects perceive candidates with liberal issue positions as more liberal and vice versa for conservative candidates. Objectively, accurate perceptions by subjects would rate a liberal candidate as " 9 " on the

Table 2. Physical appearance, issue agreement, and vote intention probability.

\begin{tabular}{|c|c|c|c|c|}
\hline Independent variables & Pair 1 appearance ++ & Pair 2 appearance + & Pair 1 appearance - & Pair 2 appearance - \\
\hline Ideology & $(0.173)$ & $(0.173)$ & $(0.173)$ & $(0.178)$ \\
\hline Liberal issue agreement & $0.777 * \quad(0.205)$ & $(0.203)$ & $(0.194)$ & $(0.210)$ \\
\hline Feminist issue agreement & $0.302^{\dagger} \quad(0.185)$ & $0.086 \quad(0.189)$ & $0.244 \quad(0.189)$ & $0.365^{\dagger} \quad(0.202)$ \\
\hline Electability rating & $0.710 * * *(0.114)$ & $0.861 * *(0.132)$ & $0.971 * *(0.109)$ & $0.850 * *(0.111)$ \\
\hline Constant & $1.065 \quad(0.896)$ & $1.295 \quad(0.911)$ & $\begin{array}{ll}-1.696 & (0.769)\end{array}$ & $0.128 \quad(0.789)$ \\
\hline Adjusted $R^{2}$ & 0.526 & 0.500 & 0.589 & 0.548 \\
\hline
\end{tabular}

OLS analysis; coefficients are unstandardized, standard errors in parentheses.

${ }^{\dagger} p<.10,{ }^{*} p<0.05, * * p<0.01, * * p<0.001$ 


\section{Schubert, Curran, and Strungaru}

Appearance++

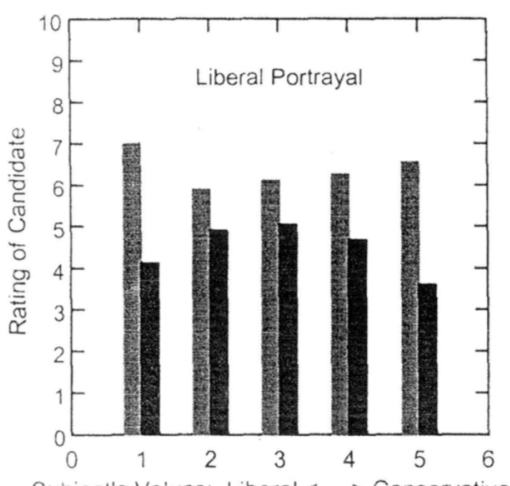

Subject's Values: Liberal <----> Conservative
Appearance--
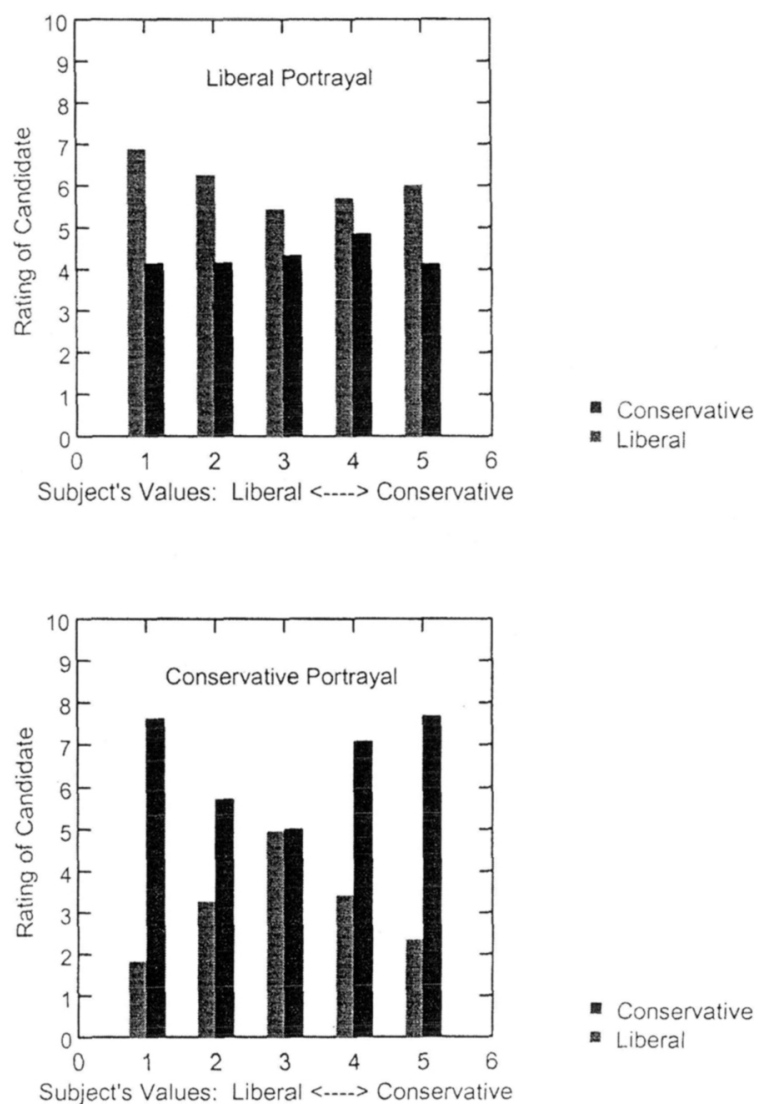

Figure 4. Assimilation of candidate issue positions: Pair 1 candidates.

liberalism scale and " 1 " on the conservative scale. Deviation from these conditions on either scale reveals perceptual error or distortion in candidate appraisal.

Figure 4 reveals that such distortion is not randomly distributed for subject ideology but varies with the reported intensity of subjects' attitudes. Thus, politically moderate subjects display the greatest error while very liberal and very conservative subjects tend to display the least. On the one hand, it is plausible that self-identified moderates are less sophisticated in relating candidate issue positions to ideological labels. On the other, when self-identified liberal or very liberal subjects minimize the conservatism of a conservative candidate, we can say there is an assimilation effect.

There is evidence of perceptual assimilation in the appraisal of Pair 1 candidates shown in Figure 4. Most striking is the contrast between the more and less attractive candidates under the conservative portrayal condition. Here, ideologically extreme subjects displayed high levels of discriminatory accuracy in rating the less attractive candidate, with very liberal and very conservative subjects similarly rating the candidate very high on conservatism and very low on liberalism. Very conservative subjects showed a similarly accurate evaluation of the more attractive candidate. Liberal and very liberal subjects clearly minimized the candidate's conservatism and maximized his liberalism, although these effects are much weaker under the condition of liberal portrayal with conservative subjects.

We then measured perceptual error in subjects' appraisal of candidate ideology by calculating the absolute value of the difference between ratings of the candidates on the liberalism and conservatism scales. 


\section{Assimilation effects in candidate appraisal}

Table 3. Assimilation effects on probability of voting for candidates.

\begin{tabular}{|c|c|c|c|c|c|}
\hline \multirow{3}{*}{$\begin{array}{l}\text { Independent variables } \\
\text { Newspapers }\end{array}$} & Pair 1 appearance ++ & Pair 2 appearance + & Pair 2 appearance - & \multicolumn{2}{|c|}{ Pair 2 appearance - } \\
\hline & $-0.299^{\dagger} \quad(0.159)$ & $(0.173)$ & -0.131 & 0.065 & $(0.165)$ \\
\hline & $0.277^{\dagger} \quad(0.149)$ & -0.058 & $(0.157)$ & -0.241 & $(0.157)$ \\
\hline Liberal issue agreement & $0.836 * *(0.134)$ & $0.720 * * *(0.140)$ & $0.555 * * *(0.132)$ & $0.334 *$ & $(0.139)$ \\
\hline Feminist issue agreement & $0.302 * * *(0.126)$ & $0.052 \quad(0.139)$ & $0.324 * *(0.136)$ & $0.385 * *$ & $(0.140)$ \\
\hline Electability rating & $0.707 * * *(0.081)$ & $0.824 * * *(0.100)$ & $0.980 * * *(0.080)$ & $0.812 * * *$ & $(0.078)$ \\
\hline Assimilation/ contrast & $-0.109 * \quad(0.050)$ & $-0.155 * * \quad(0.570)$ & $0.059 \quad(0.050)$ & -0.034 & $(0.053)$ \\
\hline Constant & $(0.716)$ & $(0.721)$ & $(0.661)$ & 0.590 & $(0.646)$ \\
\hline Adjusted $R^{2}$ & 0.557 & 0.483 & 0.576 & 0.561 & \\
\hline
\end{tabular}

OLS analysis; coefficients are unstandardized, standard errors in parentheses.

${ }^{\dagger} p<.10, * p<0.05, * * p<0.01, * * p<0.001$

Whether presented as liberals or conservatives, ratings with no distortion would have a value of 9 on a 9-point scale. Maximum distortion, in which candidates were equally rated near the midpoint of the scales, would have a value of zero. The greater the ideological difference between candidates and voters, the less likely the assimilation of candidate ideology; the smaller the difference, the greater the possibility of assimilation.

We next examined assimilation effects on vote intention for the four candidates in conjunction with electability ratings and issue agreement. We also included two indicators of media attention-frequency of reading newspapers and watching television news programs-assuming that subjects with more political information would be more adept at relating candidate issue positions with ideological labels. Results presented in Table 3 show significant assimilation effects only for the two politically attractive candidates. Thus, the greater the error in appraisal of attractive candidates' ideology, the greater the vote intention-holding electability, issue agreement, and media attention constant. An examination of the mean perceptual error across the four candidates found no significant differences. It is not the sheer amount of error in perception that explains the differences in Table 3, but the increasing frequency of error under conditions of issue disagreement for the attractive candidates. This result is consistent with the hypothesized assimilation of political values of the more attractive candidates.

Table 3 illustrates that with the effects of media attention and perceptual error controlled, the contribution of issue agreement to vote intention is strong and significant across all four candidates, in contrast to the findings in Table 2. However, effect size increases with attractiveness, and the enhanced contribution of the cognitive component to vote intention leaves the influence of the precognitive, appearance-based electability component virtually unchanged. In sum, physical appearance affects vote intention directly, as well as through indirect effects on the integration and processing of cognitive information appraisal.

\section{Discussion}

Several studies show that emotional responses to candidates for popular leadership office play an important role in voters' choices. Marcus and MacKuen $^{58}$ revealed the involvement of feelings of anxiety and enthusiasm, Granberg ${ }^{2}$ reported on both U.S. and cross-national research demonstrating that affective response, even "gut level" feelings, may trigger favorable perceptual distortions of candidates' views, while Sullivan and Masters ${ }^{59}$ showed that voters respond emotionally and differentially to candidates' facial displays. This study addressed two additional questions. First, do physical appearances contribute to voters' emotional responses to candidates, helping to explicate gut level feelings? And, second, how do affective and cognitive dimensions of candidate appraisal interact to influence voter decisions?

The research design separated and manipulated the affective and cognitive dimensions of candidate appraisal. First, based on prior research, subjects were exposed to candidates known to elicit positive or negative affective responses. Second, we required subjects to choose between candidates under conditions of cognitive agreement or disagreement. Subjects responded with both their heads and their hearts-or guts, as the case may be. They showed a strong preference for the candidates with whom they agreed, a 


\section{Schubert, Curran, and Strungaru}

strong preference for the candidates they liked, were most responsive to candidates they both liked and agreed with, and were most negative towards those they disliked and with whom they disagreed.

The more interesting problem occurs when voters confront contradictory dispositions in their affective and cognitive responses to candidates. Subjects were somewhat more likely to vote for a less attractive candidate with whom they agreed ideologically, than an attractive candidate with whom they disagreed (Ms $=5.35$ and 4.95 for Pair 1 , and $M$ s $=5.03$ and 3.76 for Pair 2 in Table 1). On the other hand, the mean vote intention for the less attractive candidate was only at the mid-point (5.0) on the vote intention scale under agreement conditions. This result was reinforced when considering the overall partial contribution of agreement on discrete issues to vote intention. Issue agreement made a significant and substantial contribution to vote intention only for the attractive candidates.

The findings reveal this effect to be partially the result of perceptual assimilation in which subjects exaggerated the similarity of the candidates' positions with their own. However, subjects were more responsive to cognitive information when considering attractive candidates, even with assimilation effects statistically controlled. In other words, positive affective response was a prerequisite for cognitive processing of issue information for many of our subjects. These subjects, acting as cognitive misers, dismissed those candidates from consideration who they deemed unelectable based on physical appearance. The findings demonstrate that cognitive and affective dimensions of candidate appraisal are mutually reinforcing when they contain consistent information, that positive affect does not trump cognitive agreement when they are inconsistent, but that positive affective may enhance the cognitive component of candidate appraisal.

There is little doubt that physical appearances play a role in the selection of mating partners, chief executive officers, generals, even football quarterbacks. The proposition that appearances play a role in the selection of political leaders may be more provocative because it appears to contradict traditional models of the rational voter while challenging democratic norms of equal opportunity. One implication of these findings is that attractive candidates have a decided competitive advantage in nominating contests and runoff elections. General elections are becoming the province of attractive candidates who meet stereotypic expectations of leader appearance. Appearance-based selection biases operate early in the electoral process: in the surfacing period before primary elections, during campaigns to achieve party nominations, and at nominating conventions. Candidates whose appearance and behavioral style meet the standard of electability may be more effective in raising campaign funds, garnering media attention, receiving endorsements, and enjoying critical early success in the polls. General elections with two party candidates minimize the effects of attractiveness in the formation of preferences. Here, there should be no major challenge to accepted models of voting behavior because the nomination process controls for appearance effects.

The practical implications of these findings are threefold. First, in any election, candidates who do not meet stereotypic expectations with respect to appearance and style are likely to receive less substantive consideration of their policy views than those who do meet them. Second, in multi-candidate elections such as primaries, where two or more candidates with similar political views compete, candidates who are more attractive should enjoy a decided advantage resulting from voters' implicit biases. Third, in runoff or general election contests in which there is a significant attractiveness contrast between candidates, the more attractive candidate will receive the benefit of assimilation effects in candidate appraisal.

\section{Conclusion}

This study investigated the role of physical appearance in candidate appraisal, based on theory and research in the fields of evolutionary psychology and facial processing in cognitive neuroscience. Specifically, we tested the hypotheses that attractiveness is associated with electability and electability with vote intention; that appearance-based electability judgments affect vote intention independent of issue agreement; that the effects of issue agreement are stronger for more electable candidates; and, that voters assimilate their issue disagreements with more electable candidates during information processing, leading to greater vote intention than would occur on the basis of appearance or issue agreement alone. An experimental design tested these hypotheses by juxtaposing two pairs of 


\section{Assimilation effects in candidate appraisal}

attractive and unattractive candidates as very liberal or very conservative, based on information provided in campaign brochures.

Candidates who are more attractive are not necessarily guaranteed electoral wins. Issue agreement is also important, and no doubt determinative in runoff elections. Issue effects could work either for or against an attractive candidate, depending on how much voters agree with them, although assimilation effects give candidates who are more attractive an edge. We propose that precognitive processing of visual information about candidates, in conjunction with implicit, predisposed preferences for selective aspects of facial morphology, prime the processing of semantically encoded information about candidates; our results support this model.

\section{Note}

The research upon which this paper is based was supported by Grant Number R03 MH58152-01A1 to the first author from the National Institute of Mental Health, Department of Health and Human Services, Washington, DC. Its contents are solely the responsibility of the authors and do not represent the official views of the National Institute of Mental Health. A version of this paper was originally presented at the 2001 annual meeting of the Midwest Political Science Association, Chicago, IL, April 19-22, 2001.

\section{References}

1. James M. Carlson, " Subjective ideological similarity between candidates and supporters," Political Psychology, 1990, 11: 485-492.

2. Donald Granberg, "Political perception," in Explorations in Political Psychology, Shanto Iyengar and William I.

McGuire, eds (Durham, NC: Duke University Press, 1993), pp. 70-112.

3. Linda A. Jackson, Physical Appearance and Gender: Sociobiological and Sociocultural Perspectives (Albany: State University of New York Press, 1992).

4. Kathryn E. Lewis and Margaret Bierly, "Toward a profile of the female voter: Sex differences in perceived physical attractiveness and competence of political candidates," Sex Roles, 1990, 22: 1-12.
5. Shawn W. Rosenberg, Lisa Bohan, Patrick McCafferty, and Kevin Harris, "The image and the vote: The effect of candidate presentation on voter preference," American Journal of Political Science, 1986, 30: 108-127.

6. Lee Sigelman, Carol Sigelman, and Christopher Flower, "A bird of a different feather? An experimental investigation of physical attractiveness and the electability of female candidates," Social Psychology Quarterly, 1987, 50: 32-43.

7. Richard S. Wyer Jr., Thomas L. Budesheim, Sharon Shavitt, Ellen D. Riggle, R. Jeffery Melton, and James H. Kuklinski, "Image, issues, and ideology: The processing of information about political candidates," Journal of Personality and Social Psychology, 1991, 61: 535-545.

8. Amotz Zahavi, "Mate selection: A selection for a handicap," Journal of Theoretical Biology, 1975, 53: 205214.

9. Randy Thornhill and Steven W. Gangestad, "Human facial beauty: Averageness, symmetry, and parasite resistance," Human Nature, 1993, 4: 237-269.

10. Karl Grammar and Randy Thornhill, "Human facial attractiveness and sexual selection: The roles of averageness and symmetry," Journal of Comparative Psychology, 1994, 108: 233-242.

11. Paul Ekman and Erika Rosenberg eds, What the Face Reveals: Basic and Applied Studies of Spontaneous Expression Using the Facial Action Coding System (New York: Oxford University Press, 1997).

12. Andrew W. Young, Face and Mind (New York: Oxford University Press, 1998).

13. James N. Schubert, Carmen Strungaru, Margaret Ann Curran, and Wulf Schiefenhovel, "Physische ereheinung und die einschatzung von politischen kandidatinnen und kandidaten," in Biopolitics: Politikwissenschaft jenseits des kulturismus, Klaus Kamps and Meredith Watts, eds (BadenBaden: Nomos, 1998), pp. 159-178.

14. Monika L. McDermott, "Voting cues in low-information elections: Candidate gender as a social information variable in contemporary United States elections," American Journal of Political Science, 1997, 41: 270-284.

15. David J. Gopoian, "Issue preferences and candidate choice in presidential primaries," American Journal of Political Science, 1982, 26: 523-546.

16. Barbara Norrander, "Correlates of vote choice in the 1980 primaries," Journal of Politics, 1986, 48: 156-166.

17. Richard S. Wyer, Jr. and Victor C. Ottati, "Political information processing," in Explorations in Political Psychology, Shanto Iyengar and William J. McGuire, eds (Durham, NC: Duke University Press, 1993), pp. 264-295. 


\section{Schubert, Curran, and Strungaru}

18. Samuel L. Popkin, "Decision making in presidential primaries," in Explorations in Political Psychology, Shanto Iyengar and William J. McGuire, eds (Durhman, NC: Duke University Press, 1993), pp. 361-379.

19. Donald Granberg, Jeff Kasmer, and Tim Nanneman, "An empirical examination of two theories of political perception," Western Political Quarterly, 1988, 41: 29-46.

20. Mary L. Phillips, Edward T. Bullmore, Robert Howard, Peter W. R. Woodruff, Ian C. Wright, Steven C. R. Williams, Andrew Simmons, Christopher Andrew, Michael Brammer, and Anthony S. David, "Investigation of facial recognition memory and happy and sad facial expression perception: An fMRI study," Psychiatry Research: Neuroimaging Section, 1998, 83: 127-138.

21. Itzhak Freid, Katherine A. MacDonald, and Charles L. Wilson, "Single neuron activity in human hippocampus and amygdala during recognition of faces and objects," Neuron, 1997, 18: 753-765.

22. Hans C. Breiter, Nancy L. Etcoff, Paul J. Whalen, William A. Kennedy, Scott L. Rauch, Randy L. Buckner, Monica M. Strauss, Steven E. Hyman, and Bruce R. Rosen, "Response and habituation of the human amygdala during visual processing of facial expression," Neuron, 1996, 17(5): $875-887$.

23. A. Mike Burton, "A model of human face recognition," in Localist Connectionist Approaches to Human Cognition, Jonathon Grainger and Arthur M. Jacobs, eds (Mahwah, NJ: Lawrence Erlbaum, 1998), pp. 75-100.

24. Semir Zeki, "Parallel processing, asynchronous perception, and a distributed system of consciousness in vision," The Neuroscientist, 1998, 4: 365-372.

25. J. Bruno Debruille, Francois Guillem, and Bernard Renault, "ERPs and chronometry of face recognition: Following-up Seeck et al. and George et al.," NeuroReport, 1998, 9: 3349-3353.

26. Milton Lodge, Marco Steenbergen, and Shawn Brau, "The responsive voter: Campaign information and the dynamics of candidate evaluation," American Political Science Review, 1995, 89: 309-326.

27. Russell M. Bauer and Mieke Verfaellie, "Electrodermal discrimination of familiar but not unfamiliar faces in prosopagnosia," Brain and Cognition, 1988, 8: 240-252.

28. Russell M. Bauer, “Autonomic recognition of names and faces in prosopagnosia: A neurological application of the Guilty Knowledge Test," Neuropsychologia, 1984, 22(4): 457-469.

29. Jerry A. Fodor, The Modularity of the Mind (Cambridge, MA: The MIT Press, 1983).
30. Hedrick Smith, The Power Game: How Washington Works (New York: Ballantine, 1989).

31. Sidney Kraus, ed, The Great Debates: Kennedy vs. Nixon, 1960, rev ed (Bloomington, IN: Indiana University Press, 1977).

32. Randy Thornhill and Steve W. Gangestad, "Human fluctuating asymmetry and sexual behavior," Psychological Science, 1994, 5: 297-302.

33. Rotem Kowner, "Facial asymmetry and attractiveness judgment in developmental perspective," Journal of Experimental Psychology, 1996, 22: 662-675.

34. L. R. Mealey, R. Bridgstock, and G. C. Townsend, "Symmetry and perceived facial attractiveness: A monozygotic co-twin comparison," Journal of Personality and Social Psychology, 1999, 76: 151-158.

35. Judith Langlois, Jean M. Ritter, and Lisa Musselman, "What is average and what is not average about attractive faces," Psychological Science, 1994, 5: 214-220.

36. I. S. Penton-Voak, D. I. Perrett, and J. W. Pierce, "Computer graphic studies of the role of facial similarity in judgments of attractiveness," Current Psychology, 1999, 18: 104-117.

37. Jim Pollard, John Shepard, and Jean Shepard, "Average faces are average faces," Current Psychology 1999, 18: 98103.

38. Michael R. Cunningham, "Measuring the physical in physical attractiveness: Quasi-experiments on the sociobiology of female facial beauty," Journal of Personality and Social Psychology, 1986, 50: 925-935.

39. Michael R. Cunningham, Anita P. Barbee, and Carolyn L. Pike, "What do women want? Facialmetric assessment of multiple motives in the perceptions of male facial physical attractiveness," Journal of Personality and Social Psychology, 1990, 59: 61-72.

40. Allan Mazur, Gael Mazur, and Caroline Keating, "Military rank attainment of a West Point class: Effects of cadets' physical features," American Journal of Sociology, 1984, 90: 125-151.

41. D.I. Perrett, K.J. Lee, I. S. Penton-Voiak, D. Rowland, S. Yoshikawaa, D. M. Burt, S. P. Henzil, D. L. Castles, and S. Akamatsu, "Effects of sexual dimorphism of physical attractiveness," Nature, 1998, 394: 884-887.

42. Sybil Geldart, Daphne Mauer, Katherine Carney, "Effects of eye size on adults' aesthetic ratings of faces and 5-month-olds' looking times," Perception, 1999, 28: 361374.

43. Adam J. Rubenstein, Lisa Kalakanis, and Judith $\mathrm{H}$. Langlois, "Infant preferences for attractive faces: A cognitive 


\section{Assimilation effects in candidate appraisal}

explanation," Developmental Psychology, 1999, 35: 848855 .

44. Gillian Rhodes, Alex Sumich, and Graham Byatt, "Are average facial configurations attractive only because of their symmetry?" Psychological Science, 1999, 10: 52-58.

45. Curtis Samuels, George Butterworth, Tony Roberts, Lida Graupner, and Graham Hole, "Facial aesthetics: Babies prefer attractiveness to symmetry," Perception, 1994, 23 : 823-831.

46. S. Michael Kalick, Leslie A. Zebrowitz, Judith H. Langlois, and Robert M. Johnson, "Does human facial attractiveness honestly advertise health," Psychological Science, 1998, 9: 8-13.

47. Randy Thornhill and Steve W. Gangestad, "The evolution of human sexuality," Trends in Ecology and Evolution, 1996, 11: 98-102.

48. Diego Pizzagalli, Thomas Koenig, Marianne Regard, and Dietrich Lehmann, "Faces and emotions: Brain electric field sources during covert emotional processing,"

Neurosychologia, 1998, 36: 323-332.

49. Ellen Berscheid and Elaine Walster, "Physical attractiveness," in Advances in Experimental Social Psychology, vol. 7, Leonard Berkowitz, ed (New York: Academic Press, 1974), pp. 157-215.

50. Carol Keating, Allan Mazur, Marshall H. Segall, Paulo G. Cysneiros, William T. Divale, Janet E. Kilibride, Suntaree Komin, Peter Leahy, Blake Thurman, Rolf Wirsing, "Culture and the perception of social dominance from facial expression," Journal of Personality and Social Psychology, 1981, 40: 615-626.

51. Carol Keating, Allan Mazur, and Marshall H. Segall, “A cross-cultural exploration of physiognomic traits of dominance and happiness," Ethology and Sociobiology, 1981, 2: 41-48.

52. Allan Mazur and Ulrich Mueller, "Channel modeling: From West Point cadet to general," Public Administration Review, 1996, 56: 191-198.

53. Ulrich Mueller and Allan Mazur, "Facial dominance," in Research in Biopolitics, vol. 4, Al Somit and Steven A. Peterson, eds (Greenwich, CT: JAI Press, 1996), pp. 99111.

54. Allan Mazur and Alan Booth, "Testosterone and dominance," Behavioral and Brain Sciences, 1998, 21: $353-$ 397.

55. Leslie A. Zebrowitz, Luminita Voinescu, and Mary Ann Collins, "'Wide-eyed' and 'crooked-faced': Determinants of perceived and real honesty across the life span," Personality and Social Psychology Bulletin, 1996, 22: 1258-1269.

56. Leonie Huddy and Nayda Terkildsen, "Gender stereotypes and the perception of male and female candidates," American Journal of Political Science, 1993, 37: 119-147.

57. Mark Fey, 'Stability and coordination in Duverger's Law: A formal model of pre-election polls and strategic voting," American Political Science Review, 1997, 91: 135147.

58. George E. Marcus and Michael B. MacKuen, "Anxiety, enthusiasm, and the vote: The emotional underpinnings of learning and involvement during presidential campaigns," American Political Science Review, 1993, 87: 672-685.

59. Denis G. Sullivan and Roger Master, "Happy warriors: leaders, facial displays, viewers' emotions, and political support," American Journal of Political Science, 1988, 32: 345-368. 